\title{
Asystasia (Acanthaceae) in Malaysia
}

\begin{abstract}
Three taxa of Asystasia, the naming of which has been confused, occur in Peninsular Malaysia. None is native. A. nemorum Nees (syn. A. intrusa Blume, non (Forssk,) Nees) from Java has only been collected from Penang and Singapore. A. gangetica (L.) T. Anderson is widespread and is represented by two subspecies: a large-flowered taxon, subsp. gangetica (syn. A. coromandeliana Nees) which is a long-established introduction from India and a small-flowered taxon, subsp. micrantha (Nees) Ensermu (syn. A. intrusa (Forssk.) Nees) which is a recent introduction, probably from Africa. A key to the three taxa in Malaysia is provided.
\end{abstract}

Keyword: Asystasia; Malaysia 